\title{
Human and animal cystic echinococcosis in Konya, Turkey: molecular identification and the first report of $E$. equinus from human host in Turkey
}

\author{
Salih Macin ${ }^{1}\left(\mathbb{D} \cdot\right.$ Serra Orsten $^{2} \cdot$ Rugıyya Samadzade $^{1} \cdot$ Bayram Colak $^{3} \cdot$ Hakan Cebeci $^{4} \cdot$ Duygu Fındık $^{1}$
}

Received: 1 July 2020 / Accepted: 7 January 2021 / Published online: 19 January 2021

(C) The Author(s), under exclusive licence to Springer-Verlag GmbH, DE part of Springer Nature 2021

\begin{abstract}
Cystic echinococcosis is a neglected, zoonotic disease in Turkey. The disease is commonly seen in rural areas where the local population is in close contact with livestock and dogs. This research aimed to molecularly identify of hydatid cysts in cattle and human isolates from Konya, Turkey. Following sample collection, direct microscopy was performed. After direct examination, total DNA was extracted, and positive PCR products of cox 1 mitochondrial gene $(\sim 875 \mathrm{bp})$ were sequenced. A total of 83 hydatid cysts (cattle $n=57$ and human $n=26$ ), 82 were identified as Echinococcus granulosus sensu stricto (G1-G3 genotypes), and one human isolate was characterized as Echinococcus equinus (G4 genotype). Fertility rates of cysts belonging to cattle for liver and lung cysts were $93.3 \%$ and $80 \%$, respectively. Out of 26 human originated isolates, $18(69.2 \%)$ of cysts were found to be fertile. To the best of our knowledge, this is the first report of E. equinus from human host in Turkey.
\end{abstract}

Keywords Echinocccus granulosus sensu lato $\cdot$ Human cystic echinococcosis $\cdot$ Echinococcus equinus $\cdot$ Turkey $\cdot$ Cattle

\section{Introduction}

Cystic echinococcosis (CE) is a zoonotic disease of the species Echinococcus granulosus sensu lato (s.l) in humans and herbivorous animals and causes public health problems in many parts of Europe, including Turkey, as well as Middle East, Central Asia, Northern and Eastern Africa, Australia, and South America (Eckert et al. 2001; Sadjjadi 2006; Galeh et al. 2018). E. granulosus causes an accidental human infection; adult tapeworms are found in the intestines of canines

Section Editor: Bruno Gottstein

Salih Macin

salihmacin@hotmail.com

1 Faculty of Medicine, Department of Medical Microbiology, Selçuk University, Konya, Turkey

2 Vocational School of Health Services, Hacettepe University, Ankara, Turkey

3 Faculty of Medicine, Department of General Surgery, Selçuk University, Konya, Turkey

4 Faculty of Medicine, Department of Radiology, Selçuk University, Konya, Turkey (dog, wolf); the larval cyst stage is present in the viscera of herbivores (sheep, cattle, horse, deer, pig, camel) (King 2005). Transmission to human occurs via the fecal-oral route (Tamarozzi et al. 2020).

Clinical symptoms in CE can vary according to the size, location, and condition of the cyst (Erdoğan et al. 2017). When cysts are ruptured, fever, urticaria, anaphylactic shock, and death can be observed. Diagnosis is made by clinical findings, radiological imaging techniques, serological, and molecular microbiological methods (King 2005).

E. granulosus s.l includes a number of genetic variants. According to recent findings, E. granulosus s.l has been split into E. granulosus sensu stricto (G1-G3 genotypes), E. equinus (G4 genotype), E. ortleppi (G5 genotype), E. Canadensis cluster (G6/7, G8, G10), and Echinococcus felidis (Casulli et al. 2019, Knapp et al. 2015; Nakao et al. 2013). E. granulosus s.s. (G1 genotype) has the most wide geographic distribution around the world and also dominant in the Mediterranean area (Varcasia et al. 2007; Busi et al. 2007). Genetic variations may determine the life-cycle pattern phenotypic characteristics, host specificity, antigenicity, transmission dynamics, infection route, sensitivity to antimicrobial agents and vaccine development strategies, epidemiology, and control of echinococcosis (Thompson and Mc Manus 
2001). From Turkey, CE has been reported in intermediate hosts such as, sheep, cattle, goats, water buffaloes, mouflon, horse, and pigs (Simsek et al. 2011; Utuk and Simsek 2013; Umur 2003; Yildiz and Gurcan 2003; Yildiz and Tunçer 2005; Esatgil and Tuzer 2007; Kose and Sevimli 2008).

Determination of species is important in control programs because of variations in the period of egg production in some strains (Eryıldız and Sakru 2012). CE is endemic in Turkey, but molecular data of E. granulosus s.l infecting humans and animals are still limited some of areas where the local population is in close contact with dogs and livestock. The aim of this study molecularly identifies E. granulosus s.l isolates from hydatid cyst material of different intermediate/aberrant hosts (humans and livestock animals) in Konya province, Turkey.

\section{Material and methods}

\section{Sample collection}

Hydatid cyst samples were collected from 60 cattle from slaughterhouse in Konya province of Turkey. In the slaughtered centers, internal organs (primarily liver and lung) were checked by palpation and inspection to collect hydatid cyst material from animals. After examinations, cyst contents were collected from the organs to the tubes by aspirating with thick-tipped, sterile injectors. A total of 26 patients who received percutaneous treatment or surgery from March 2018 to June 2019 were included in this study. All the patients were originated from Konya, Turkey.

\section{Direct microscopy}

Hydatid cyst fluids were centrifuged at $4000 \mathrm{rpm}$ for $15 \mathrm{~min}$ in order to precipitate the protoscoleces in cyst fluid. After centrifugation, $100-\mu l$ pellet was transferred to the slide and was examined under a light microscope at $\times 40$ objective. Samples with hook or protoscoleces in microscopy were accepted as fertile.

\section{DNA isolation, amplification, sequencing, and analyses}

The genomic DNA was extracted from pellet of hydatid fluid using the Thermo Blood and Tissue DNA Extraction Kit (Qiagen, Hilden, Germany) according to the manufacturer's instructions. The obtained DNA was used as a template for an 880 -bp part of the cytochrome c oxidase subunit $1(\operatorname{cox} 1)$ mitochondrial gene amplification as previously described (Nakao et al. 2010). After amplification, all the products were performed electrophoresis in $1.5 \%$ agarose gels and visualized under ultraviolet light. All positive amplicons were identified via sequencing.
FinchTV 1.4.0 (Geospiza Inc., Seattle, WA, USA) was used for analyzing sequencing data. The obtained sequences were examined by BLAST for comparing with present sequences in the NCBI database. Additionally, sequences were analyzed as explained previously by Boufana et al. (2014). Concisely, sequences were aligned in Mega version 7 (Tamura et al., 2013) and ClustalX (Larkin et al., 2007). Hapview was performed to generate haplotype network (Salzburger et al., 2011).

\section{Ethical considerations}

The study protocol followed ethical guidelines of the Declaration of Helsinki. An informed consent that explained the purposes, benefits, and risks of the study was signed by the patients. Ethical approval has been provided by the Ethics Committee from the Faculty of Medicine, Selçuk University $(21 / 02 / 2018-2018 / 62)$.

\section{Results}

In the present study, a total of 60 hydatid cysts retrieved from cattle and 26 hydatid cysts originated from human were investigated. Seventy-five percent (45/60) of the cysts that belong to cattle have been found in the liver; $25 \%(15 / 60)$ of them were located in the lungs. There is no mixed infection in cattle. According to microscopic examination, $90 \%$ (54/60) of examined cysts were identified as fertile; the rest of them were as non-fertile. Among 54 fertile cysts, $77.8 \%$ (42/54) and 22.2\% $(12 / 54)$ were located in the liver and the lungs, respectively.

A total of 26 human originated cysts were examined under light microscopy. As a result, $69.2 \%$ (18/26) of cysts were found to be positive in terms of protoscoleces presence.

According to cox 1 amplification results, 95\% (57/60) of cysts belong to cattle and $100 \%$ (26/26) of cysts that originated from human were evaluated as positive. Three PCR-negative cattle isolates are classified as non-fertile. All positive amplicons were characterized via sequencing. All the products were confirmed by the BLAST algorithm as E. granulosus s.l. A total of 82 isolates were identified as E. granulosus s.s. and one isolate as E. equinus (G4 genotype). The obtained sequence of $E$. equinus is submitted to GenBank (accession number: MT621047). As a result of the haplotype analysis, it was determined that there are 33 haplotypes with high genetic diversity (Hd $0.926 \pm 0.00035$ ) (Fig. 1). The main haplotype cluster was $99.14 \%$ identical to E. granulosus s.s. (accession no. AB491446). The other dominant haplotype cluster was $100 \%$ identical to E. granulosus s.s. (accession no. AB491414). Additionally, a phylogenetic tree was constructed using with some reference sequences (Supplementary Figure). 
Fig. 1 Haplotype network constructed using partial sequences of the cox 1 gene of Echinococcus granulosus s.s. belong to human and cattle from Turkey

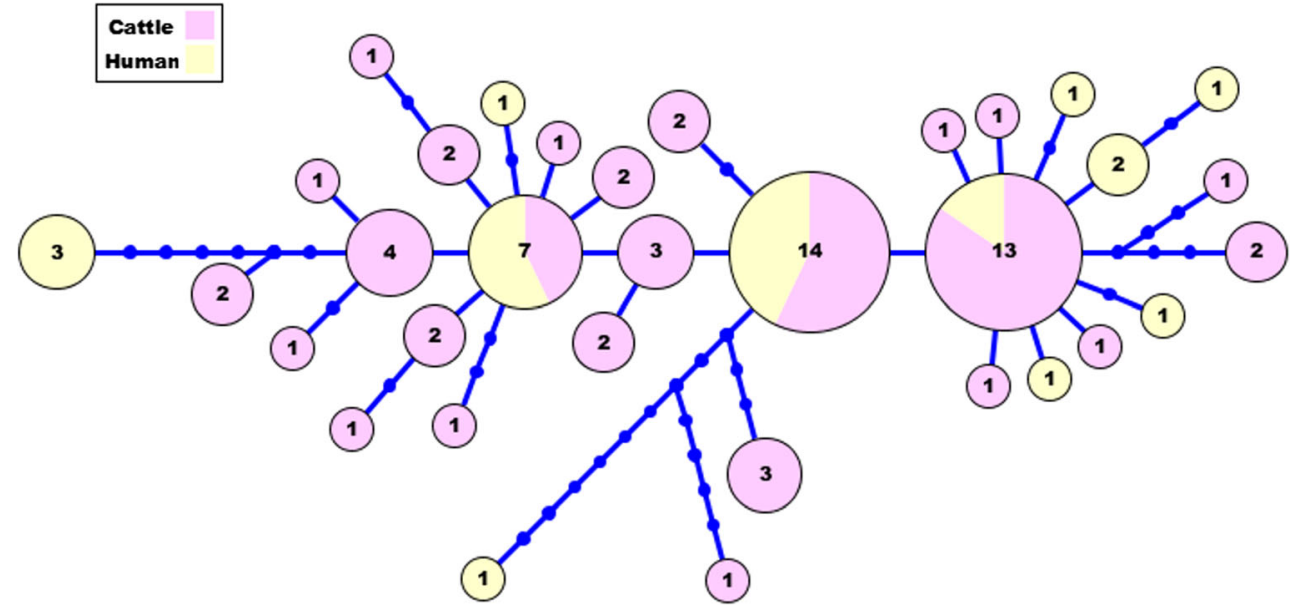

\section{Discussion}

In this study, the molecular characterization of E. granulosus s.1 is investigated in infected intermediate hosts including humans and cattle from Konya, Turkey. Molecular diversity was sought via cox 1 mitochondrial gene amplification and sequencing. As a result, all the isolates collected in this study were confirmed by BLAST algorithm as E. granulosus s.l. From Turkey, there are several reports on molecular characterization of E. granulosus s.l isolates from various intermediate hosts (Schneider et al. 2008; Utuk et al. 2008; Snabel et al. 2009; Ergin et al. 2010; Simsek et al. 2011; Utuk and Simsek 2013; Bakal et al. 2015; Eroglu et al. 2016; Orsten et al. 2018; Kurt et al. 2020; Örsten et al. 2020). These studies showed that E. granulosus s.s. (genotypes G1-G3) is the predominant species obtained from hydatid materials in Turkey. Our findings are consistent with previous studies. Among 83 isolates included in this study, 82 were confirmed as E. granulosus s.s. (G1$\mathrm{G} 3$ genotypes). Although E. canadensis (G7 genotype) was not detected in this study, it had been reported in human host from Izmir Province in the Aegean region (Snabel et al. 2009) and Edirne in the Thrace region (Erylldz et al. 2012). In the recent study, E. canadensis (G6 genotype) was reported in sheep from Elazığ (Mehmood S et al. 2020)

As a result of the analyses, it has been observed that sheep and cattle have the same haplotypes with humans. This result revealed the importance of sheep and cattle in autochthonous transmission (Orsten et al. 2018). Consistent with this assessment, some haplotypes were found to be common for humanand cattle-derived isolates in this study. These results confirmed that cattle are involved in autochthonous transmission in Turkey. Sheep are accepted as the most important intermediate host for continuity of the life cycle of $E$. granulosus s.s. (Deplazes et al. 2017). Whereas several studies are reported that sheep-derived cysts showed high fertility and viability, cattle-derived cysts are generally sterile (Abiyot et al. 2011; Fikire et al. 2012). A study from Turkey reported the fertility rates of hydatid cysts from sheep as 81.53 and $76.47 \%$ for liver and lung cysts, respectively (Yildiz and Gurcan 2003). Although there are studies about the spread of hydatid cysts found in cattle in Turkey, a limited number of publications investigated the fertility of hydatid cysts in cattle. Hydatid cysts derived from cattle showed lower cyst fertility as $6.6 \%$ in Kırıkkale (Yildiz and Tunçer 2005), 5.42\% in Afyonkarahisar (Kose et al. 2008). In the present study, fertility rates of cysts that belong to cattle were quite higher as 93.3 and $80 \%$ for liver and lung cysts, respectively. There is conflicting reports on fertility rates in cattle from European countries (Umhang et al. 2014a, 2014b; Chihai et al. 2016; Founta et al 2016). This may indicate that cattle also contribute to the cycle of E. granulosus s.s. (Cardona and Carmena 2013).

According to published data, E. granulosus s.s. (G1-G3 genotypes) is the most common species of $88.44 \%$ of the human $\mathrm{CE}$ cases in worldwide. The following genotypes are G6/G7 cluster (E. canadensis) with $11.07 \%$ (Alvarez Rojas et al. 2014). The obtained results in this study are consistent with previous findings. In detail, among 26 human-derived hydatid cyst, 25 were characterized as E. granulosus s.s. (G1-G3 genotype). One isolate belonging to a human host was identified as Echinococcus equinus (G4 genotype).

E. equinus had been characterized as a distinct subspecies of E. granulosus due to its morphological and epidemiological differences from sheep strains (Williams and Sweatman 1963). Subsequent studies have confirmed that biological differences between horse originated isolates and others (Kumaratilake et al. 1986; Smyth 1977). Before three decades, this distinction has been confirmed via partial sequencing of cox 1 gene from three hydatid cyst isolates from horses (the UK and Spain) and a donkey (Ireland) (Bowles et al. 1992). Today, there are a lot of reports indicating the presence of E. equinus from different intermediate hosts worldwide (Thompson and McManus 2002; Boufana et al. 2012). E. equinus have been detected from mule and donkey according to reports from Turkey (Simsek and Cevik 2014; Kesik 
et al. 2019). Although according to Ponce et al., E. equinus is usually developed into sterile small cysts in the intermediate hosts; other studies report a quite high rate of fertility and welldeveloped hydatid cysts (Ponce Gordo and Cuesta 1998; Varcasia et al. 2008; Simsek and Cevik 2014).

To date, E. equinus is accepted as specific to Equidae family. However, there is a study conducted on molecular characterization of E. granulosus s.l with the PCR-RFLP technique and reported E. equinus from the human host for the first time (Nakao et al. 2013; Romig et al. 2017). This study is the first report of human-derived hydatid cyst isolate as E. equinus from Turkey. Clinical findings of our patient are recorded; abdominal ultrasonography and computed tomography revealed 3 cystic lesions with stretched borders. Two of these cysts were Gharbi type 3 with the size of 5 and $6 \mathrm{~cm}$ in diameter. Third cyst was Gharbi type 1 with the size of $3 \mathrm{~cm}$ in diameter. The patient was treated with PAIR (puncture, aspiration, injection, and reaspiration) and percutaneous catheterization techniques. Patient was given orally albendazol with the dose of $10 \mathrm{mg} / \mathrm{kg}$ per day for 3 weeks before treatment session. Treatment procedure was performed under sedation with midazolam $(0.3 \mathrm{mg} / \mathrm{kg})$ and phentanyl $(50 \mu \mathrm{g})$. Followup ultrasonography examinations were performed at 1,6 , and 12 months after treatment. Lesions were totally cured and recurrence was not observed. The hemagglutination inhibition test for hydatidosis is found to be positive. The cyst is found to be sterile after microscopic examination. Despite there is evidence that E. equinus is in circulation in Turkey (Simsek and Cevik 2014; Kesik et al. 2019), we are not able to definite comment on how transmission occurs. Based on previous findings, dogs may get $E$. equinus infection from hydatid cysts that belongs to equids via unregulated slaughter (Boufana et al 2015). Although these findings are not sufficient to make an inference by oneself, they will be a source for further studies.

\section{Conclusion}

In conclusion, we investigated molecular identification of hydatid isolates originated from cattle and human from Konya province in Turkey. To the best of our knowledge, our study is the first report on the molecular confirmation of E. equinus via the sequencing of hydatid material derived from the human host in Turkey and second report in worldwide. Previous reports on $E$. equinus in intermediate hosts and our finding indicate that this species is circulating in Turkey. Further studies on the molecular epidemiology of cystic echinococcosis in Turkey are needed.

Supplementary Information The online version contains supplementary material available at https://doi.org/10.1007/s00436-021-07050-w.
Funding This project is supported by the Selcuk University Scientific Research Coordination Centre (project number: BAP/18401134).

\section{Compliance with ethical standards}

Conflict of interest The authors declare that they have no conflict of interest.

\section{References}

Abiyot J, Beyene D, Abunna F (2011) Prevalence of hydatidosis in small ruminants and its economic significance in Modjo Modern Export Abattoir, Ethiopia. J Public Health Epidemiol 3:454-461

Alvarez Rojas CA, Romig T, Lightowlers MW (2014) Echinococcus granulosus sensu lato genotypes infecting humans - review of current knowledge. Int J Parasitol 44:9-18. https://doi.org/10.1016/j. ijpara.2013.08.008

Bakal U, Simsek S, Kazez A (2015) Surgical and molecular evaluation of pediatric hydatid cyst cases in eastern Turkey. Korean J Parasitol 53: 785-788. https://doi.org/10.3347/kjp.2015.53.6.785

Boufana B, Stidworthy MF, Bell S, Chantrey J, Masters N, Unwin S, Wood R, Lawrence RP, Potter A, McGarry J, Redrobe S, Killick R, Foster AP, Mitchell S, Greenwood AG, Sako Y, Nakao M, Ito A, Wyatt K, Lord B, Craig PS (2012) Ecinococcus and Taenia spp. from captive mammals in the United Kingdom. Vet parasitol 190: 95-103. https://doi.org/10.1016/j.vetpar.2012.05.023

Boufana B, Lahmar S, Rebai W et al (2014) Genetic variability and haplotypes of Echinococcus isolates from Tunisia. Trans R Soc Trop Med Hyg 108:706-714

Bowles J, Blair D, McManus DP (1992) Genetic variants within the genus Echinococcus identified by mitochondrial DNA sequencing. Mol Biochem Parasitol 54:165-174. https://doi.org/10.1016/01666851(92)90109-w

Busi M, Snábel V, Varcasia A, Garippa G, Perrone V, De Liberato C, D'Amelio S (2007) Genetic variation within and between G1 and G3 genotypes of Echinococcus granulosus in Italy revealed by multilocus DNA sequencing. Vet Parasitol 150:75-83. https://doi. org/10.1016/j.vetpar.2007.09.003

Cardona GA, Carmena D (2013) A review of the global prevalence, molecular epidemiology and economics of cystic echinococcosis in production animals. Vet parasitol 192:10-32. https://doi.org/10. 1016/j.vetpar.2012.09.027

Deplazes P, Rinaldi L, Alvarez Rojas CA, Torgerson PR, Harandi MF, Romig T, Antolova D, Schurer JM, Lahmar S, Cringoli G, Magambo J, Thompson RC, Jenkins EJ (2017) Global distribution of alveolar and cystic echinococcosis. Adv Parasitol 95:315-493. https://doi.org/10.1016/bs.apar.2016.11.001

Eckert J, Schantz PM, Gasser RB, Torgerson PR, Bessonov AS, Movsessian SO (2001) Geographic distribution and prevalence. In: Eckert J, Gemmell MA, Meslin FX, Pawlowski ZS (eds) WHO/OIE Manual on echinococcosis in human and animals: a public health problem of global concern. World Organisation for Animal Health, Paris, pp 100-142

Erdoğan E, Özkan B, Mutlu F, Karaca S, Șahin İ (2017) Molecular characterization of Echinococcus granulosus isolates obtained from different hosts. Mikrobiyol Bul 51:79-86. https://doi.org/10.5578/ mb. 45452

Ergin S, Saribas S, Yuksel P, Zengin K, Midilli K, Adas G, Arikan S, Aslan M, Uysal H, Caliskan R, Oner A, Kucukbasmaci O, Kaygusuz A, Torun MM, Kocazeybek B (2010) Genotypic characterisation of Echinococcus granulosus isolated from human in Turkey. Afr J Microbiol Res 4:551-555 
Eroglu F, Genc A, Koltas IS (2016) The genotyping of Echinococcus granulosus isolates with PCR-RFLP Methods in Adana Province. Zirve Med J 1:22-25

Eryıldız C, Sakru N (2012) Molecular characterization of human and animal isolates of Echinococcus granulosus in the Thrace Region, Turkey. Balkan Med J 29:261-267. https://doi.org/10.5152/ balkanmedj.2012.072

Esatgil MU, Tuzer E (2007) Prevalence of hydatidosis in slaughtered animals in Thrace, Turkey. Türkiye Parazitol Derg 31:41-45

Fikire Z, Tolosa T, Nigussie Z, Macias C, Kebede N (2012) Prevalence and characterization of hydatidosis in animals slaughtered at Addis Ababa abattoir, Ethiopia. J Parasitol Vector Biol 4:1-6

Galeh TM, Spotin A, Mahami-Oskouei M, Carmena D, Rahimi MT, Barac A, Ghoyounchi R, Berahmat R, Ahmadpour E (2018) The seroprevalence rate and population genetic structure of human cystic echinococcosis in the Middle East: a systematic review and meta-analysis. Int J Surg 51:39-48. https://doi.org/10.1016/j.ijsu.2018.01.025

Kesik HK, Kilinc SG, Simsek S, Gul A (2019) Occurrence of liver hydatid cysts in a donkey and molecular characterization of Echinococcus equinus. J Parasitol 105:442-445. https://doi.org/10. $1645 / 19-3$

King CH (2005) Cestodes (Tapeworms). In: Mandell GL, Bennet JE, Dolin R (eds) Mandell, Douglas, and Bennett's principles and practice of infectious diseases, 6th edn. Elsevier Churchill Livingstone, Philadelphia, pp 3285-3293

Knapp J, Gottstein B, Saarma U, Millon L (2015) Taxonomy, phylogeny and molecular epidemiology of Echinococcus multilocularis: from fundamental knowledge to health ecology. Vet Parasitol 213:85-91. https://doi.org/10.1016/j.vetpar.2015.07.030

Kose M, Sevimli KF (2008) Prevalence of cystic echinococcosis in slaughtered cattle in Afyonkarahisar. Turkiye Parazitol Derg 32: 27-30

Kumaratilake LM, Thompson RCA, Eckert J (1986) Echinococcus granulosus of equine origin from different countries possess uniform morphological characteristics. Int J Parasitol 16:529-540. https:// doi.org/10.1016/0020-7519(86)90089-5

Kurt A, Avcioglu H, Guven E, Balkaya I, Oral A, Kirman R, Bia MM, Akyuz M (2020) Molecular characterization of Echinococcus multilocularis and Echinococcus granulosus from cysts and formalin-fixed paraffin-embedded tissue samples of human isolates in northeastern Turkey. Vector Borne Zoonotic Dis Online ahead of print. 20:593-602. https://doi.org/10.1089/vbz.2019.2594

Nakao M, Yangıda T, Okomoto M, Knapp J, Nkouawa A, Sako Y, Ito A (2010) State-of-the-art Echinococcus and Taenia: phylogenetic taxonomy of human pathogenic tapeworms an its application to molecular diagnosis. Infect Genet Evol 10:444-452. https://doi.org/10. 1016/j.meegid.2010.01.011

Nakao M, Lavikainen A, Yanagida T, Ito A (2013) Phylogenetic systematics of the genus Echinococcus (Cestoda: Taeniidae). Int J Parasitol 43:1017-1029. https://doi.org/10.1016/j.ijpara.2013.06.002

Orsten S, Boufana B, Ciftci T, Akinci D, Karaagaoglu E, Ozkuyumcu C, Casulli A, Akhan O (2018) Human cystic echinococcosis in Turkey: a preliminary study on DNA polymorphisms of hydatid cysts removed from confirmed patients. Parasitol Res 117:1257-1263. https://doi.org/10.1007/s00436-018-5807-9

Örsten S, Çiftçi T, Azizova A, Yüce G, Uysal A, İmamoğlu Ç, Karaağaoğlu E, Akıncı D, Akyön Y, Casulli A, Akhan O (2020) Investigation of the relationship between $\mathrm{CE}$ cyst characteristics and genetic diversity of Echinococcus granulosus sensu lato in humans from Turkey. Parasitology. 147(14):1712-1717. https://doi.org/10. 1017/S0031182020001535

Ponce Gordo F, Cuesta BC (1998) Observations on the Echinococcus granulosus horse strain in Spain. Vet Parasitol 76:65-70. https:// doi.org/10.1016/s0304-4017(97)00087-3
Romig T, Deplazes P, Jenkins D, Giraudoux P, Massolo A, Craig PS, De La Rue M (2017) Ecology and life cycle patterns of Echinococcus species. Adv parasit 95:213-314. https://doi.org/10.1016/bs.apar. 2016.11.002

Sadjjadi SM (2006) Present situation of echinococcosis in the Middle East and Arabic North Africa. Parasitol Int 55:197-202. https:// doi.org/10.1016/j.parint.2005.11.030

Schneider R, Gollackner B, Edel B, Schmid K, Wrba F, Tucek G, Walochnik J, Auer H (2008) Development of a new PCR protocol for the detection of species and genotypes (strains) of Echinococcus in formalin-fixed, paraffin-embedded tissues. Int J Parasitol 38: 1065-1071. https://doi.org/10.1016/j.ijpara.2007.11.008

Simsek S, Cevik A (2014) First detection and molecular characterization of Echinococcus equinus in a mule in Turkey. Acta parasitol 59: 773-777

Simsek S, Balkaya I, Ciftci AT, Utuk AE (2011) Molecular discrimination of sheep and cattle isolates of Echinococcus granulosus by SSCP and conventional PCR in Turkey. Vet Parasitol 178:367369. https://doi.org/10.1016/j.vetpar.2011.01.033

Smyth MB (1977) Effectively given domains. Theor Comput Sci 5:257274

Snabel V, Altintas N, D'Amelio S, Nakao M, Romig T, Yolasigmaz A, Gunes K, Turk M, Busi M, Hüttner M, Sevcová D, Ito A, Altintas N, Dubinský P (2009) Cystic echinococcosis in Turkey: genetic variability and first record of the pig strain (G7) in the country. Parasitol Res 105:145-154. https://doi.org/10.1007/s00436-009-1376-2

Thompson RCA, Mc Manus DP (2001) Aetiology: parasites and life cycles. In: Eckert J, Gemmell MA, Meslin FX, Pawlowski ZS (eds) WHO/OIE manual on echinococcosis in human and animals: a public health problem of global concern. World Organisation for Animal Health, Paris, pp $1-19$

Thompson RA, McManus DP (2002) Towards a taxonomic revision of the genus Echinococcus. Trends Parasitol 18:452-457. https://doi. org/10.1016/s1471-4922(02)02358-9

Umhang G, Chihai O, Boué F (2014a) Molecular characterization of Echinococcus granulosus in a hyperendemic European focus, the Republic of Moldova. Parasitol Res 113:4371-4376. https://doi. org/10.1007/s00436-014-4112-5

Umhang G, Richomme C, Hormaz V, Boucher JM, Boué F (2014b) Pigs and wild boar in Corsica harbor Echinococcus canadensis G6/7 at levels of concern for public health and local economy. Acta trop 133:64-68. https://doi.org/10.1016/j.actatropica.2014.02.005

Umur S (2003) Prevalence and economic importance of cystic echinococcosis in slaughtered ruminants in Burdur, Turkey. J Vet Med B 50:247-252. https://doi.org/10.1046/j.1439-0450.2003.00667.x

Utuk AE, Simsek S (2013) Molecular characterization of the horse isolate of Echinococcus granulosus in Turkey. J Helminthol 87:305-308. https://doi.org/10.1017/S0022149X12000363

Utuk AE, Simsek S, Koroglu E, McManus DP (2008) Molecular genetic characterization of different isolates of Echinococcus granulosus in east and southeast regions of Turkey. Acta Trop 107:192-194. https://doi.org/10.1016/j.actatropica.2008.05.026

Varcasia A, Canu S, Kogkos A, Pipia AP, Scala A, Garippa G, Seimenis A (2007) Molecular characterization of Echinococcus granulosus in sheep and goats of Peloponnesus, Greece. Parasitol Res 101:1135-1139. https://doi.org/10.1007/ s00436-007-0568-x

Varcasia A, Garippa G, Pipia AP, Scala A, Brianti E, Giannetto S, Micagni G (2008) Cystic echinococcosis in equids in Italy. Parasitol res 102:815-818. https://doi.org/10.1007/s00436007-0862-7

Williams RJ, Sweatman GK (1963) On the transmission, biology and morphology of Echinococcus granulosus equinus, a new subspecies of hydatid tapeworm in horses in Great Britain. Parasitology 53: 391-407. https://doi.org/10.1017/s0031182000073844 
Yildiz K, Gurcan S (2003) Prevalence of hydatidosis and fertility of hydatid cysts in sheep in Kırıkkale, Turkey. Acta Vet Hung 51: 181-187. https://doi.org/10.1556/AVet.51.2003.2.6

Yildiz K, Tunçer C (2005) Prevalence of hydatid cysts in cattle in the province of Kırıkkale. Turkiye Parazitol Derg 29:247-250

Tamarozzi F, Legnardi M, Fittipaldo A, Drigo M, Cassini R (2020) Epidemiological distribution of Echinococcus granulosus s.l. infection in human and domestic animal hosts in European Mediterranean and Balkan countries: A systematic review. PLoS Negl Trop Dis 14(8):e0008519

Casulli A, Siles-Lucas M, Tamarozzi F (2019) Echinococcus granulosus sensu lato. Trends Parasitol 35(8):663-664

Chihai O, Umhang G, Erhan D, Boué F, Tălămbuță N, Rusu Ș, Zamornea M (2016) Slaughterhouse survey of cystic echinococcosis in cattle and sheep from the Republic of Moldova. J Helminthol 90(3):27983

Founta A, Chliounakis S, Antoniadou Sotiriadou K, Koidou M, Bampidis V (2016) Prevalence of hydatidosis and fertility of hydatid cysts in food animals in Northern Greece. Vet Ital 52(2):123-7

Boufana B, Lett W, Lahmar S, Griffiths A, Jenkins DJ, Buishi I, Engliez SA, Alrefadi MA, Eljaki AA, Elmestiri FM, Reyes MM, Pointing S, Al-Hindi A, Torgerson PR, Okamoto M, Craig PS (2015) Canine echinococcosis: genetic diversity of Echinococcus granulosus sensu stricto (s.s.) from definitive hosts. J Helminthol 89(6):689-98

Publisher's note Springer Nature remains neutral with regard to jurisdictional claims in published maps and institutional affiliations. 